\title{
Thraustochytrids as novel parasitic protists of marine free-living flatworms: Thraustochytrium caudivorum sp. nov. parasitizes Macrostomum lignano
}

\author{
Lukas Schärer · Dagmar Knoflach · Dita B. Vizoso • \\ Gunde Rieger · Ursula Peintner
}

Received: 8 November 2006/ Accepted: 20 June 2007/Published online: 18 July 2007

(C) Springer-Verlag 2007

\begin{abstract}
The Labyrinthulomycota are a relatively poorly studied group of heterotrophic unicellular eukaryotes. They comprise three lineages, labyrinthulids, thraustochytrids, and aplanochytrids, which are all primarily marine organisms and considered to be important components of marine microbial communities. Recently a number of Labyrinthulomycota have been implicated as parasites of marine (but also terrestrial) plants and marine molluscs. Here we describe a new species of thraustochytrid, Thraustochytrium caudivorum sp. nov. that we have isolated from laboratory cultures of Macrostomum lignano (Rhabditophora, Macrostomorpha), a marine free-living flatworm. In these worms $T$. caudivorum can cause lesions, which start at the tip of the tail plate and which can lead to the dissolution of the posterior part of the animal. Although the worms can frequently cure these lesions and regenerate the lost parts, the lesions can also result in the complete dissolution of the
\end{abstract}

Communicated by M. Wahl.

Electronic supplementary material The online version of this article (doi:10.1007/s00227-007-0755-4) contains supplementary material, which is available to authorized users.

L. Schärer · D. Knoflach · D. B. Vizoso · G. Rieger

Division of Ultrastructural Research and Evolutionary Biology, Institute of Zoology, University of Innsbruck, Innsbruck, Austria

U. Peintner

Institute of Microbiology, University of Innsbruck,

Innsbruck, Austria

L. Schärer $(\bowtie)$

Evolutionary Biology, Zoological Institute, University of Basel,

Vesalgasse 1, 4051 Basel, Switzerland

e-mail: lukas.scharer@unibas.ch animal. We describe this thraustochytrid based on pure agar cultures and infestations in the worm cultures. Moreover, we describe its pathological effects on the worms and its morphology using both light and electron microscopy. In addition, we report a phylogenetic analysis using a partial $18 \mathrm{~S}$ rDNA sequence that allows us to place this new species within the thraustochytrids. Finally, we outline a protocol that allows to permanently remove the parasites from infested worm cultures. We conclude that thraustochytrids represent a novel group of parasites of free-living flatworms.

\section{Introduction}

The Labyrinthulomycota are an enigmatic and relatively poorly studied group among the eukaryotic protists (Raghukumar 2002). They include three groups of marine heterotrophic stramenopiles, the labyrinthulids, the thraustochytrids and the aplanochytrids (Leander et al. 2004) (the taxon aplanochytrids is synonymous with the taxon formerly called labyrinthuloids, see Leander and Porter 2000). These organisms are considered to be important members of marine microbial communities, and they can be extremely abundant (Raghukumar 2002). In addition, some species seem to extend into brackish and terrestrial environments (Raghukumar 2002).

Recently, several members of the Labyrinthulomycota have been implicated as parasites. Some labyrinthulids have been shown to parasitize marine plants (e.g., sea grass, Jensen et al. 1998) and terrestrial plants irrigated with high-salt irrigation water (e.g., ornamental turf grass, Bigelow et al. 2005; Craven et al. 2005), whereas some thraustochytrids can cause considerable problems in 
aquaculture of marine molluscs (e.g., abalone, Bower 1987, hard-shell clam, Ragan et al. 2000, see Raghukumar 2002 for a review). Finally, Labyrinthulomycota have been identified as important obstacles to establish stable in vitro cell cultures in a number of marine invertebrates (summarized by Rinkevich 1999).

Here we describe the new species Thraustochytrium caudivorum sp. nov., which we have isolated from laboratory cultures of the recently described free-living flatworm, Macrostomum lignano (Platyhelminthes: Rhabditophora: Macrostomorpha) (Ladurner et al. 2005), and which can cause severe pathological effects in these worms. We describe these pathological effects and the characteristics of a thraustochytrid infestation in worm culture. Further, we outline techniques to maintain $T$. caudivorum in pure in vitro culture and show its growth characteristics in these cultures. Moreover, we morphologically describe different stages of $T$. caudivorum that we have observed within the tissues of this flatworm using transmission electron microscopy. Finally, we report on molecular analyses that permit the phylogenetic placement of this new species of thraustochytrid.

\section{Materials and methods}

The flatworm M. lignano

Macrostomum lignano is a free-living flatworm from the interstitial sand fauna of the Northern Adriatic Sea (Ladurner et al. 2000, Ladurner et al. 2005). It is an obligately outcrossing simultaneous hermaphrodite that reaches $1.5 \mathrm{~mm}$ in length and has a generation time of only 18 days (Schärer and Ladurner 2003; Schärer et al. 2004). $M$. lignano has recently been suggested as a new model organism among the lower Bilateria and is used for studies of stem cell biology, regeneration and sexual selection (Ladurner et al. 2005). Mass cultures of M. lignano are maintained in glass Petri dishes in $\mathrm{f} / 2$, which is an artificial seawater medium (Andersen et al. 2005), in a climatecontrolled room at $20^{\circ} \mathrm{C}, 60 \%$ relative humidity, with a 14:10 h light:dark cycle, and fed with the diatom, Nitzschia curvilineata (Tyler 1981; Rieger et al. 1988).

Observations in worm cultures

Thraustochytrid infested worm cultures and infected M. lignano were observed under a dissecting microscope (Nikon, SMZ-2B), an inverse compound microscope (Zeiss, Axiovert 135) or a compound microscope (Leitz Diaplan) at varying magnifications. Samples of infested cultures were further observed on a compound microscope (Leica DM 5000 B) using a 100× oil objective.
In vitro culture of thraustochytrids

In vitro cultures of thraustochytrids were established from two sources in our laboratory: (a) from cultures of $M$. lignano (called strain S4), and (b) from cultures of the acoel Isodiametra pulchra (called strain SJ), of which we are also maintaining long-term cultures. However, as the main emphasis of our work was on $M$. lignano, possible pathologic effects on I. pulchra were not investigated. For standard culture both strains were cultivated on SSA medium (Serum Seawater Agar, Leander et al. 2004, but with $1 \%$, not $0.01 \%$, of horse serum, D. Porter, personal communication) or on growth medium M (Mo et al. 2002, but without germanium dioxide). Media were prepared from artificial seawater (hw sea salt professional, Wiegandt $\mathrm{GmbH}$, Germany). To both media we routinely added $250 \mathrm{mg} \mathrm{l}^{-1}$ of streptomycin (Sigma S9137) and/or ampicillin (Sigma A9518), unless we wanted to check if cultures were free of bacteria. The growth medium $\mathrm{M}$ is richer and leads to faster growth and larger mounds of thraustochytrids, but it is also more prone to be overgrown by bacteria and fungi. Thraustochytrid cultures were maintained in under the same climate-controlled room as the flatworms.

To study zoospore formation we adapted a time-lapse observation method we have previously established to study the mating behavior of $M$. lignano (Schärer et al. 2004). Vegetative cells were sampled from dense mounds on growth medium $\mathrm{M}$, placed in a drop of artificial sea water in an observation chamber and filmed at $400 \times$ magnification at one frame per $15 \mathrm{~s}$. From the resulting movies we extracted two sequences and report them here as supplementary material (see Results).

\section{Transmission electron microscopy}

Affected animals were relaxed in a solution of $\mathrm{MgCl}_{2} \cdot 6 \mathrm{H}_{2} \mathrm{O}$ (7.14\%), fixed for $1 \mathrm{~h}$ in $2.5 \%$ glutaraldehyde in $0.1 \mathrm{M}$ cacodylate buffer ( $\mathrm{pH} 7.2$ ) containing $10 \%$ sucrose, postfixed for $1 \mathrm{~h}$ with $1 \%$ osmium tetroxide in $0.1 \mathrm{M}$ cacodylate buffer, dehydrated in a standard acetone series, and embedded in Spurr's low viscosity resin (Spurr 1969). Ultra-thin sections were cut with a Reichert Ultracut UCT. Sections were double-stained with uranyl acetate and lead citrate and examined with a Zeiss LIBRA 120 transmission electron microscope.

\section{Molecular methods}

In order to extract DNA from single zoospore cultures freshly prepared zoospore solutions were diluted serially in three steps of $1: 100$ and these dilutions plated on growth medium $\mathrm{M}$ agar plates. After 1 week of incubation 
small colonies were picked and transferred to liquid medium (1\% horse serum in artificial seawater) in sterile tissue culture flasks $\left(25 \mathrm{~cm}^{2}\right.$, TPP, Switzerland) and allowed to grow for several days. DNA was isolated from dense liquid cultures using a standard CTAB extraction protocol (Zolan and Pukkila 1986) or the UltraClean ${ }^{\mathrm{TM}}$ Plant DNA Kit (MO BIO Laboratories, USA) following the instructions of the manufacturer. Primers used for PCR amplification and sequencing of the gene coding for the $18 \mathrm{~S}$ (SSU) ribosomal RNA were NS1, NS3, NS4 and NS8 (White et al. 1990). Amplification protocols followed conditions described by Vilgalys and Hester (1990) and Gardes and Bruns (1993). The components of the PCR were: $15 \mu \mathrm{l}$ of master mix and $10 \mu \mathrm{l}$ of diluted DNA extract. The following DNA-extract dilutions were tested: $1: 10,1: 50$ or $1: 100$. The final concentration in a reaction volume of $25 \mu \mathrm{l}$ was: $200 \mu \mathrm{M}$ dNTP's, $0.4 \mathrm{mM}$ of each primer, 0.75 units Taq polymerase (PeqLab), $10 \mathrm{mM}$ TMAC, $1 \mathrm{M}$ TrisHCl, $10 \mathrm{mM}$ EDTA, 5\% Glycerin, $1.5 \mathrm{mM} \mathrm{MgCl} 2,10 \mathrm{mM}$ TrisHCl, $55 \mathrm{mM} \mathrm{KCl}$ (PeqLab). Cleaned PCR products (Amicon Micron-PCR Centrifugal Filtersystem by Millipore, USA) were ligated into the vector of the TOPO TA Cloning Kit (Invitrogen, USA) and cloned into chemically competent $E$. coli cells according to the instructions of the manufacturer. Four or five clones were sequenced from each culture (MWG Biotech, Germany). Sequences were deposited in GenBank under the following accession numbers: EF114347 (clone S4-T1), EF114348 (clone S4-Type), EF114349 (clone S4-T43), EF114350 (clone S4-T5), EF114351 (clone S4-T11), EF114352 (clone S4-F7), EF114353 (clone S4-G7), EF114354 (clone S4-T41), and EF114355 (clone SJ). Reference sequences from other Labyrinthulomycota were obtained from GenBank (see Fig. 5 for accession numbers).

Sequences were aligned in Sequencher 4.5 (GeneCodes Corporation, USA) and manually adjusted with Se-Al v2.0a11 (Rambaut 1996). Maximum parsimony analyses were carried out with PAUP* $4.0 \mathrm{~b} 10$ (Swofford 2003). Regions of ambiguous alignment and regions with large insertions in out-group sequences were excluded from the analyses. Unless otherwise stated, gaps were treated as missing data. Two sequences from Labyrinthula zosterae were used as out-group (Leander and Porter 2001). The maximum parsimony analysis was conducted with 100 replicates of "random" addition sequence, 1 tree held at each step, and TBR branch swapping, the reconnection limit was set to 8 , maxtrees was set to 10,000 . Branch support was assessed by bootstrapping with simple taxon addition, NNI, with 100 replicates, ten trees held at each step (Salamin et al. 2003). Uncorrected pair-wise distances (p) were calculated in PAUP*.
Control of T. caudivorum in cultures of M. lignano

To establish a protocol to remove $T$. caudivorum from our infested cultures of $M$. lignano ten adult worms each were placed into the wells of a 24 -well cell culture plate (TTP, Switzerland) containing $300 \mu \mathrm{l}$ of artificial sea water (ASW) and allowed to lay eggs overnight. On the second day the adult worms and the ASW were removed and replaced with $1 \mathrm{ml}$ of a solution of Triton X-100 (Sigma) in ASW at five final concentrations between 0.25 and $1 \%$ or with only ASW as a control (four replicates each). Triton $\mathrm{X}-100$ is a nonionic surfactant and a powerful detergent, which is routinely used to permeabilize eukaryotic cell membranes. We expected that the different stages of the parasite would be destroyed by this treatment, but that the embryos would be protected from the action of the detergent by the eggshell. On the fourth day the Triton solution was removed and each well rinsed three times with fresh ASW to thoroughly remove remaining detergent. During the following week the wells were checked daily for emerging hatchlings, which were immediately transferred to a fresh well plate containing diatoms. Finally, we added $1 \mathrm{ml}$ of liquid medium to each of the treated wells in order to check for thraustochytrids that may have survived the treatment.

\section{Results}

Species description

Thraustochytrium caudivorum, Schärer, Knoflach, Vizoso, Rieger, Peintner sp. nov. (Figs. 1, 2, 3, 4).

Genus Thraustochytrium Sparrow 1936

\section{Diagnosis}

Cellulae vegetativae globosae, nihil mobilae, statura variabile, cellulae parvae $4.0-5.3 \mu \mathrm{m}$, cellulae magnae 10.4 $26.7 \mu \mathrm{m}$, cellulae intermediae presentiae. Numquam fissio cellularum sed cellulae crescent inflatandum. Reticulum ectoplasmaticum epi agari factum potest. Zoosporae biflagellatae, ovatae, 4.0-5.0 $\times 2.4-3.7 \mu \mathrm{m}$, numerosae. Reliquiae parietis atque rudimeni basali nullae. Cellulae segregatae ex area necrotica in caudum $M$. lignanoi. Descriptio ex observatione cellularum in culturis puris in agaro (de cultura S4), in liquido et in cellulae consociate cum infectionis M. lignanoi. Holotypus IB20060239, cultura agaro puro S4 in ATTC depositata.

Measurements in the following description were from the S4 strain grown for 1 month on SSA medium and then transferred to a slide as for time-lapse observation. The 

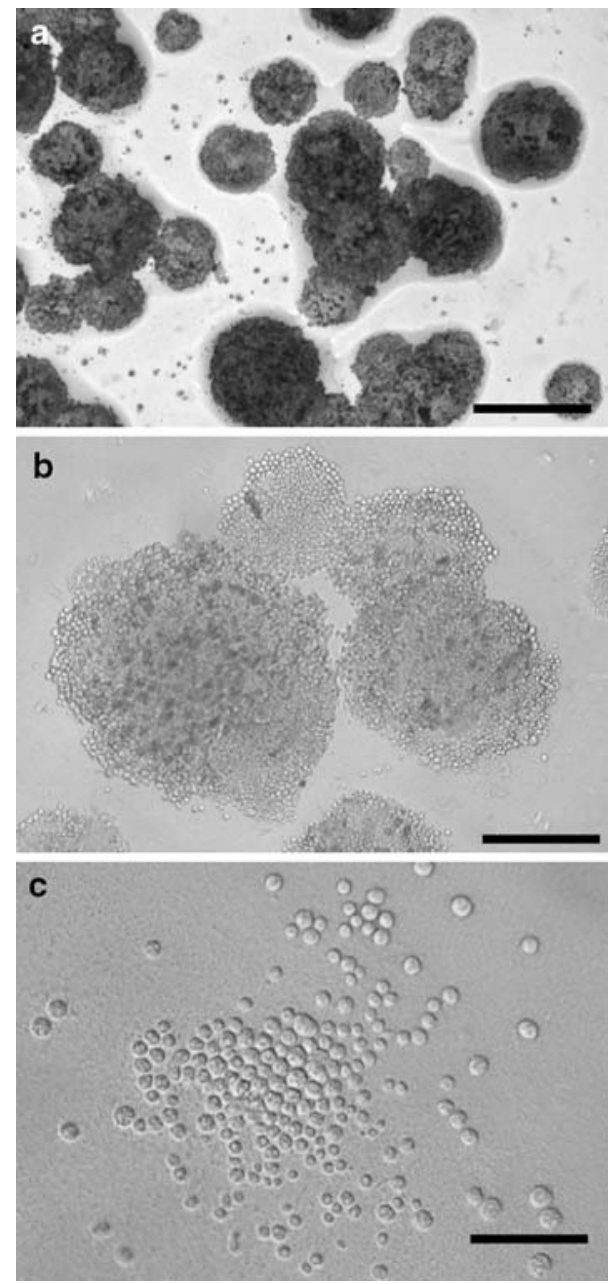

Fig. 1 Colony morphology of Thraustochytrium caudivorum in pure culture: a and $\mathbf{b}$ on growth medium $\mathrm{M} T$. caudivorum forms very dense colonies, that contain many pigmented cells (the apparent difference in pigmentation is probably due to different light conditions at the different magnifications) (a scale bar $500 \mu \mathrm{m} ; \mathbf{b}$ scale bar $200 \mu \mathrm{m}$ ) (Leitz Diaplan); c on SSA medium T. caudivorum forms much less dense colonies, which are usually not pigmented (scale bar $50 \mu \mathrm{m})$ (Leitz Diaplan)

vegetative cells are round, non-motile and highly variable in size (e.g., Fig. 1c). The smallest cells (mean diameter \pm 1SE, $4.5 \pm 0.1 \mu \mathrm{m}$, range $4.0-5.3 \mu \mathrm{m}, n=10)$ are probably freshly settled zoospores. No binary fission of such cells was ever observed. Instead cells exhibit direct growth, which leads to large round cells (mean diameter $\pm 1 \mathrm{SE}$, $14.6 \pm 1.4 \mu \mathrm{m}$, range $10.4-26.7 \mu \mathrm{m}, n=10)$. All intermediate sizes can also be observed. Under certain conditions the vegetative cells can form an ectoplasmic net on the substrate (Fig. 2c). Moreover, vegetative cells have mitochondria with tubular cristae and scaly membranes (Fig. 4f).

Zoospore formation occurs when large, presumably multinucleate, vegetative cells are placed into seawater,
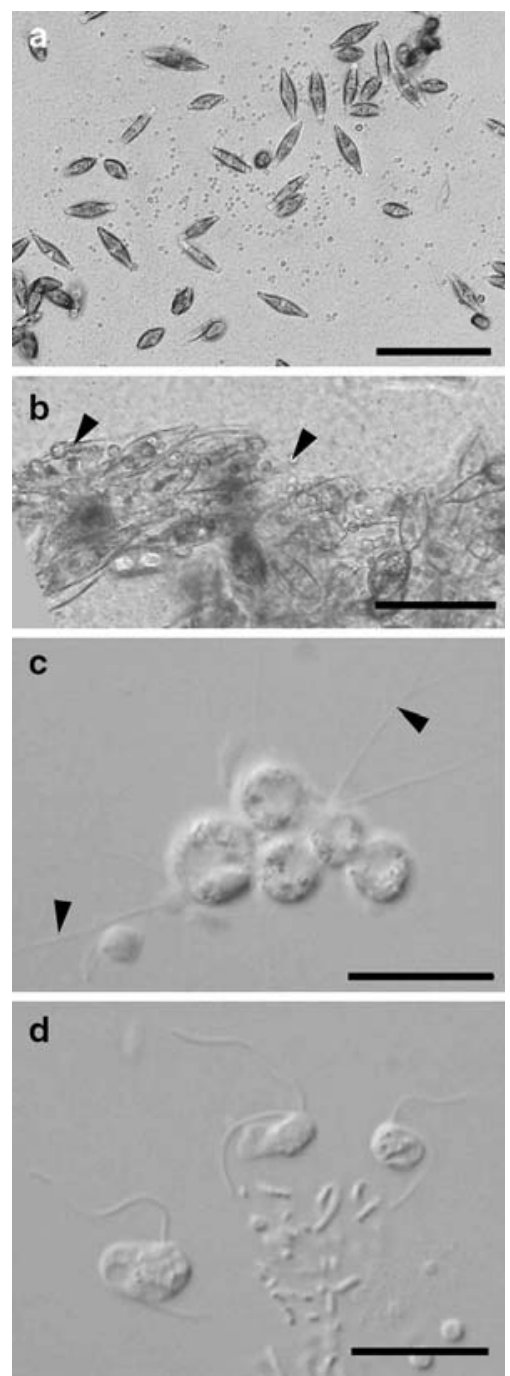

Fig. 2 Characteristics of a Thraustochytrium caudivorum infestation in cultures of Macrostomum lignano: a a cluster of vegetative T. caudivorum cells (small dots) between cells of the food diatom Nitzschia curvilineata (boat-shaped cells) (scale bar $100 \mu \mathrm{m})$ (Zeiss Axiovert 135), frequently large areas of the bottom of the culture dishes can be covered by such cells; b vegetative T. caudivorum cells (filled arrow heads) on clusters of excreted and partly digested food diatom $N$. curvilineata (scale bar $50 \mu \mathrm{m}$ ) (Zeiss Axiovert 135); c a group of vegetative $T$. caudivorum cells showing the formation of ectoplasmic nets (filled arrow heads) (scale bar $10 \mu \mathrm{m})$ (Leica DM $5000 \mathrm{~B}$ ); d three zoospores of $T$. caudivorum (and some bacteria) (scale bar $10 \mu \mathrm{m})($ Leica DM $5000 \mathrm{~B})$

and subsequently partition their cytoplasm in a synchronous way to form up to dozens of zoospores (no zoospore formation was ever observed in agar culture). No wall remnants or basal rudiments were ever observed during zoospore formation (see the supplementary Movie S1). The zoospores are biflagellate and ovoid in shape (mean length $\pm 1 \mathrm{SE}, 4.3 \pm 0.1 \mu \mathrm{m}$, range $4.0-5.0 \mu \mathrm{m}, n=10$; mean width $\pm 1 \mathrm{SE}, \quad 3.1 \pm 0.1 \mu \mathrm{m}$, range $2.4-3.7 \mu \mathrm{m}$, $n=10$ ) (Fig. 2d). 
Holotype: Voucher material was deposited in the Herbarium IB (IB20060239); the T. caudivorum strain S4 culture was deposited in the American Type Culture Collection (PRA-210) (see http://www.atcc.org).

Voucher material: Spurr embedded infected Macrostomum lignano from the worm cultures from which strain S4 was isolated. Spurr-embedded T. caudivorum of the strain S4 form SSA cultures. S4 culture on dried agar and in $100 \%$ ethanol, all under the voucher number IB20060239.

Additional material: T. caudivorum strain SJ culture deposit (PRA-211).

Etymology: The name refers to the tail-eating habit of the parasite.

Characteristics of $T$. caudivorum in pure cultures

The growth characteristics of $T$. caudivorum in in vitro culture vary with the culture media. On growth medium $\mathrm{M}$ vegetative cells form distinct mounds, in which many cells are pigmented and exhibit a rusty color (Fig. 1a, b). Here the vegetative cells show a large size variation, which suggests that they are multinucleate. In contrast, on SSA medium growth is slower, and vegetative cells form clusters of cells (Fig. 1c), but no distinct mounds (i.e., the cells generally form a mono-layer). Also the cell size variation appears smaller on this medium. In liquid medium (not shown) cells form clusters of vegetative cells, much like in worm cultures, but appear to also colonize new areas of the culture dish, probably through formation of zoospores and subsequent settlement. On agar media we never observed zoospores in the periphery of clusters or mounds.

When we transferred vegetative cells from growth medium $\mathrm{M}$ to an observation chamber with artificial seawater, we could observe two interesting phenomena. First, the cytoplasm of the presumably already multinucleate vegetative cells of different sizes began to partition itself around the presumed nuclei, leading to the formation of dozens of zoospores in the largest cells (see the supplementary Movie S1). No rupture of a sporangial wall or similar structure was ever observed. Moreover, in several cases some relatively small vegetative cells exhibited an odd extension, which performed 'searching' snake-like movements (see the supplementary Movie S2).

Characteristics of $T$. caudivorum infestations in worm cultures

In infested cultures vegetative cells of $T$. caudivorum of a range of sizes are usually observed on the floor of the culture dishes, often forming clusters (Fig. 2a). Such clusters are particularly prevalent around the packets of partly digested algae, which the worms excrete. These packets appear to be a rich source of nutrients and can be covered with a dense layer of vegetative cells (Fig. 2b). When such vegetative cells are removed from the cultures and placed on a microscope slide, cells of different sizes can be observed, which after a while may show the formation of an ectoplasmic net (Fig. 2c). Another distinct sign of infestation is the presence of zoospores in the water column. These biflagellate dispersal stages (Fig. 2d) exhibit a smooth and steady swimming path, which appears less erratic than that of some flagellates with which they could be confounded.

Pathological effects of $T$. caudivorum on the host M. lignano

The primary effect of $T$. caudivorum on M. lignano is the dissolution of the tail-plate. This usually starts at the very

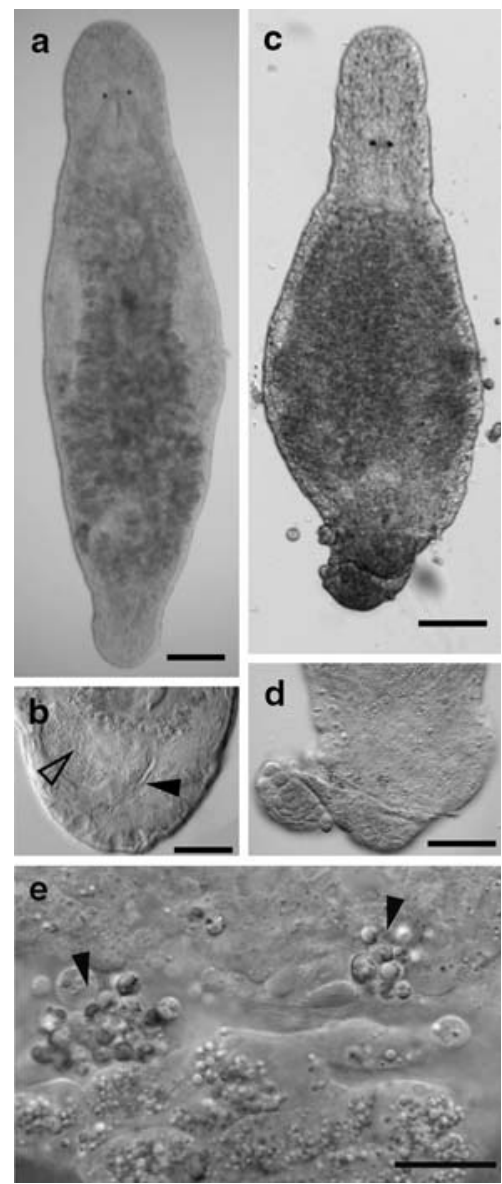

Fig. 3 Pathological effects of Thraustochytrium caudivorum on Macrostomum lignano: a a healthy M. lignano with an intact tailplate (scale bar $100 \mu \mathrm{m}$ ) (Leitz Diaplan); b an intact tail-plate with seminal vesicle (open arrow head) and stylet (closed arrow head) (scale bar $50 \mu \mathrm{m}$ ) (Leitz Diaplan); c an affected M. lignano with a dissolving tail-plate (scale bar $100 \mu \mathrm{m}$ ) (Leitz Diaplan); d a dissolving tail-plate lacking the typical reproductive structures (scale bar $50 \mu \mathrm{m})$ (Leitz Diaplan); e a detail of the tail-plate in panel d, the arrow heads indicate clusters of $T$. caudivorum cells (scale bar $10 \mu \mathrm{m})$ (Leitz Diaplan) 
tip of the tail-plate (Fig. 3a-d), and can in extreme cases lead to the dissolution of the entire worm. During the process of tissue dissolution many vegetative cells of T. caudivorum are liberated (Fig. 3e), these then probably undergo zoospore formation, and the zoospores then disperse and settle at new sites in the dish.

Ultrastructure of $T$. caudivorum cells in affected tissue of M. lignano

The lesions caused by $T$. caudivorum generally start at the tip of the tail-plate of affected M. lignano (Fig. 4a). A section through such a lesion shows that the epidermis abruptly changes from an intact to a degraded state
(Fig. 4b). Vegetative cells of T. caudivorum can be observed at locations that are several cell layers inside the host tissue (Fig. 4b), suggesting that these cells can actively penetrate the host tissue, possibly due to the observed snake-like movement. Moreover, they often appear to be surrounded by apparently intact host cells (Fig. 4c), and may contain dense vesicles. Furthermore, vegetative cells of $T$. caudivorum appear to proliferate in these sites, as multinucleate stages can be observed (Fig. 4d). Considerable amounts of vegetative thraustochytrid cells can be shed from lesions, and they show two ciliary rootlets (Fig. 4e), suggesting that they can form biflagellate stages. Moreover, the mitochondria of these cells have tubular cristae, a widespread condition in eukaryotic protists
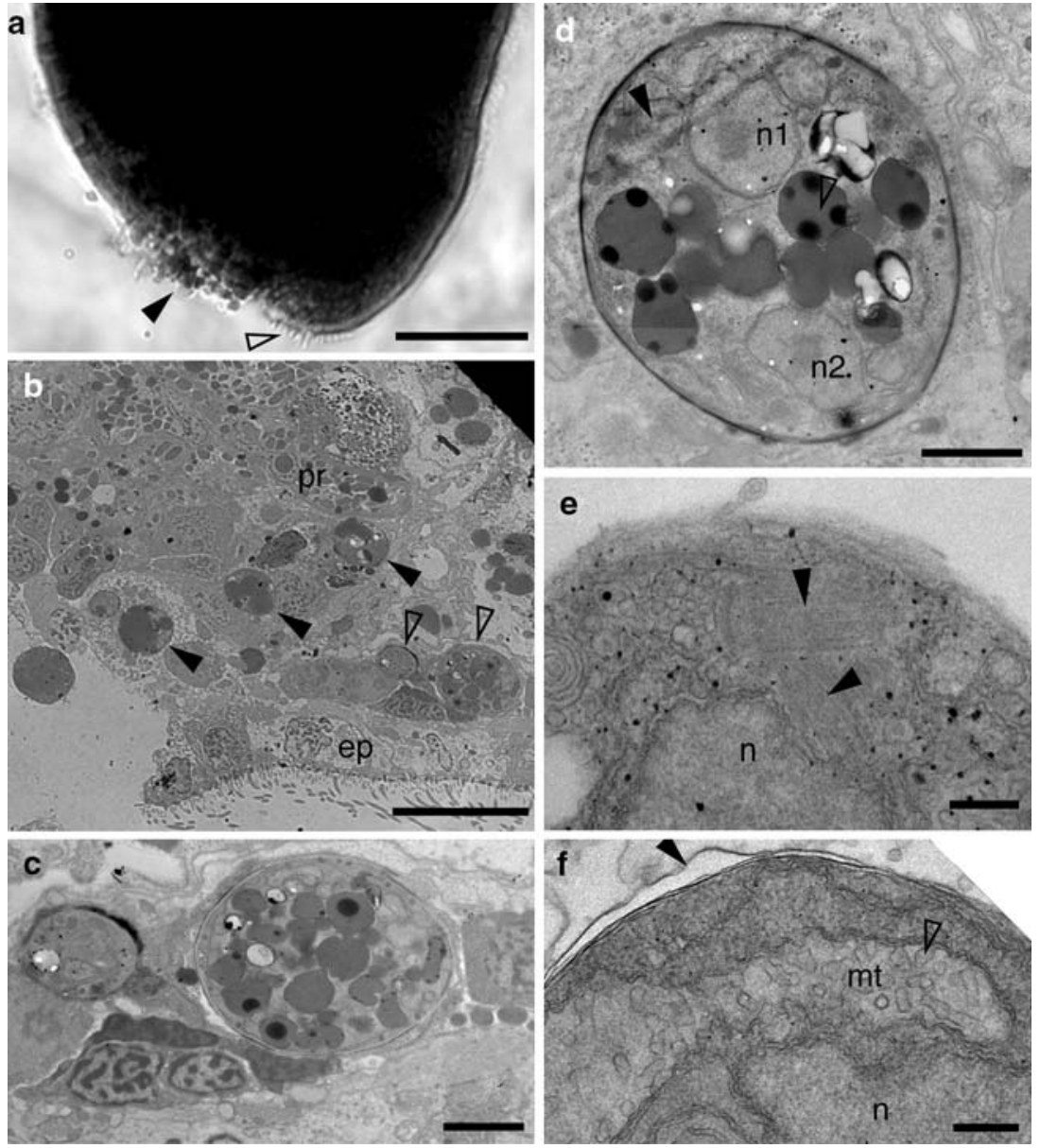

Fig. 4 Ultrastructure of Thraustochytrium caudivorum cells in affected tissue of Macrostomum lignano: a lesion on the tip of the tail-plate of a resin embedded $M$. lignano. Note the $T$. caudivorum cells and decaying host cells that emerge from the lesion (filled arrow head), and the remaining adhesive glands on the healthy part of the tail-plate (open arrow head) (scale bar $50 \mu \mathrm{m}$ ) (Leitz Diaplan); b sagittal section through the lesion in a, note the intact epidermis (ep) and prostate glands ( $p r)$, several T. caudivorum cells are embedded in host tissue (open and closed arrow heads) (scale bar $10 \mu \mathrm{m}$ ); c detail of the two T. caudivorum cells marked in panel by open arrow heads (scale bar $2 \mu \mathrm{m}) ; \mathbf{d}$ a T. caudivorum cell in a position similar to the ones marked by closed arrow heads in panel $\mathbf{b}$, note the two nuclei (n1 and n2), the mitochondria (closed arrow head) and the secretions (open arrow head) (scale bar $1 \mu \mathrm{m}$ ) (the diagonal line in the upper left corner of the panel is a sectioning artifact); e detail of a $T$. caudivorum cell emerging from a lesion, note the two ciliary rootlets (filled arrow heads) (scale bar $0.2 \mu \mathrm{m}$ ); $\mathbf{f}$ detail of a T. caudivorum cell emerging from a lesion, note the scales at the surface of the cell (filled arrow head) and the tubular cristae of the mitochondrion $(m t)$ (scale bar $0.2 \mu \mathrm{m}$ ) 
(Fig. 4f), which clearly suggests that they are not host cells. And finally, these cells exhibit scaly membranes (Fig. 4f), a typical feature of the Labyrinthulomycota.

\section{Phylogenetic analysis}

Direct sequencing of PCR products that were amplified from DNA isolated from single zoospore cultures did not yield clean sequences. Analysis of different clones resulting from one PCR reaction showed that genetic variation occurs in three regions of the SSU rDNA, and includes a total of 18 out of 1,647 nucleotide positions $(=1.01 \%)$ (Table 1$)$. The same rDNA variation was observed in clones originating from both isolates of $T$. caudivorum (i.e., $\mathrm{S} 4$ and SJ).

The alignment of the $33 \mathrm{SSU}$ sequences consisted of 1,846 characters of which 1,690 were included, 713 were constant, and 780 were parsimony informative. The maximum parsimony analysis of the dataset yielded two equally parsimonious trees [tree score $=2901$ steps, $\mathrm{CI}=$ 0.5753 , homoplasy index $(\mathrm{HI})=0.4247, \mathrm{RI}=0.7457$, rescaled consistency index $(\mathrm{RC})=0.4290]$ (Fig. 5).

The SSU rDNA sequence analysis confirmed that the Labyrinthulomycota are comprised of three main phylogenetic groups, as found by earlier studies (Leander and Porter 2001; Leander et al. 2004): the labyrinthulids, the aplanochytrids (consisting of two clades), and the thraustochytrids. Diplophrys marina is closely related to Aplanochytrids. The clade thraustochytrids is paraphyletic, as it includes Ulkenia spp., Aplanochytrium haliotidis and a sequence assigned to the genus Schizochytrium (AB052555). The position of T. multirudimentale within the clade thraustochytrids is not resolved.

All the sequences of our newly described $T$. caudivorum form a distinct and well-supported clade within the thraustochytrids (Bootstrap value 100\%), and represent a sister clade to sequences from Thraustochytriidae AB183654 and AB183659 (Fig. 5).

Uncorrected pair-wise distances within the nine $T$. caudivorum sequences are $0.0039(\mathrm{SD}=0.0022)$ and between T. caudivorum and Thraustochytriidae AB183654 and AB183659 are $0.1001 \quad(\mathrm{SD}=0.0013)$. Pair-wise distances between clades within the thraustochytrids are in a range of $0.160-0.230$, between thraustochytrids and labyrinthulids generally higher than 0.32 . Thus, pair-wise distances confirm that $T$. caudivorum is a distinct clade within the lineage Thraustochytrium, and that it should thus be considered to represent a new species.

\section{Control of $T$. caudivorum in cultures of M. lignano}

Seven days after we had terminated the Triton treatment all except three eggs had hatched. The hatchlings appeared normal, they reproduced normally once they became adult, 


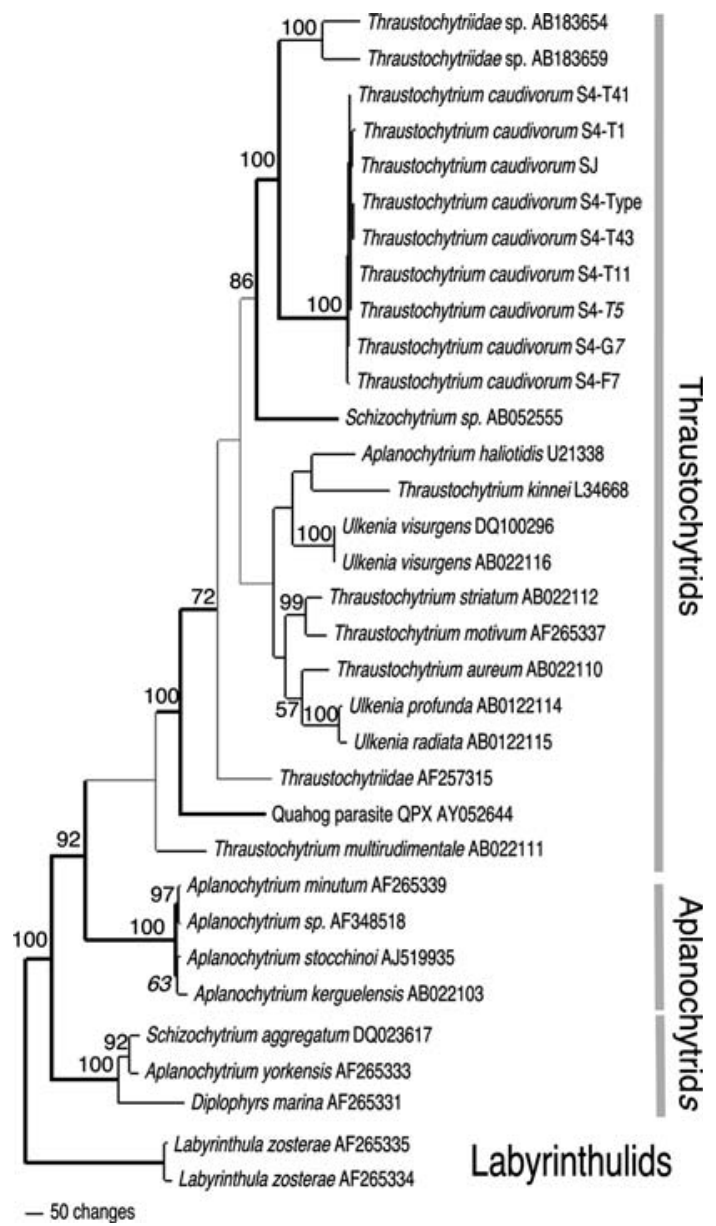

Fig. 5 Phylogram of the 18S rDNA gene showing one of two best maximum parsimony trees as calculated with the program PAUP*. Bootstrap values $>70$ are given above branches. Well-supported branches (i.e., bootstrap values $>90 \%$ ) are in bold. Grey branches have bootstrap values $<50$. $S 4$ and $S J$ denote the strain of the Thraustochytrium caudivorum isolate

and their cultures did not show signs of thraustochytrid infestation for over 8 months following treatment. During the treatment the Triton, however, seemed to lead to a delay in the time of hatching of up to 6 days beyond the expected hatching date.

No thraustochydrids were observed in the liquid medium of the Triton-treated wells, but all control wells contained both vegetative cells and zoospores, suggesting that the Triton treatment was effective at all the concentrations we tested.

\section{Discussion}

Interaction between $T$. caudivorum and M. lignano

Our results suggest that $T$. caudivorum is an opportunistic parasite of M. lignano, because large amounts of both vegetative and flagellated cells can sometimes be observed without any apparent pathological effects on the worms and because it can grow well outside of the host. Moreover, T. caudivorum infestations can be particularly drastic when worms have access to a lot of algae. Under such conditions incomplete digestion of algae may provide more growth substrate for T. caudivorum, and will lead to strong infestations. When food is more restricted, worms may digest algae more completely. Moreover, under such conditions they may also consume the vegetative cells of $T$. caudivorum. In the transmission electron microscope we repeatedly observed partly digested cells of $T$. caudivorum in the gut of worms. Such a complex interaction between the algae, the worms and the thraustochytrids could explain the often non-intuitive progression of the infestation.

\section{Transmission route of $T$. caudivorum}

We initially considered the possibility of a trophic transmission route, because advanced lesions often lead to an open-ended gut (note that the Macrostomida, as most flatworms, have no anus). However, more detailed observations suggested that the origin of the lesions was on the tip of the tail-plate. In healthy individuals this site is many cell layers away from the end of the gut and is separated by the entire male copulatory apparatus. We currently consider it likely that the infection starts in the region of the adhesive papillae, and that these organs may even be involved in picking up infective stages. The snake-like movement of vegetative cells we show in the Movie S2 may be involved in burrowing into the tissue after contact.

Interestingly, transfer of affected worms to fresh (parasite-free) culture dishes often leads to a recovery of the affected animal, and to the regeneration of the entire tailplate within a few days. This kind of regeneration appears to be very similar to the one observed after experimental removal of the tail-plate (e.g., Egger et al. 2006). This may suggest a role for freshly settling zoospores in maintaining an active lesion, and it thus appears that the presence of sufficient $T$. caudivorum can counteract the striking wound-healing and regeneration ability of these worms. Reinfection experiments and more detailed studies on the infection route are planned.

Thraustochytrids as parasites

Our study is the first to implicate thraustochytrids as parasites of free-living flatworms. However, given that an unambiguous diagnosis of Labyrinthulomycota has only recently become possible using ultrastructural and molecular approaches we consider it possible that some old observations of taxonomically ill-defined parasites of free-living flatworms could be Labyrinthulomycota. An 
example are the 'cristalloides' or 'Kristalloide' (further called crystalloids), which Hallez (1879), based on his observations in Mesostoma ehrenbergi, considered to be secretions involved in storage of energy reserves for overwintering. In his large monograph von Graff (1882, p. 182) also discussed these structures but he made no definite statement about their origin and significance. However, in a later report von Graff (1903, p. 56ff) strongly opposed Hallez' interpretation and made a strong point that these structures are of parasitic origin (without, however, suggesting to which phylogenetic group they might belong). In their monographs Bresslau (1928-33, p. 228-229) and Meixner (1938, p. 140) considered crystalloids to be Chytridiaceae (a group of fungi that occur primarily in freshwater). One reason that in fact makes it unlikely that crystalloids are thraustochytrids is that most observations are from fresh-water flatworm species and thraustochytrids are considered to be a primarily marine group. The only reports of similar structures from marine free-living flatworms are from acoels and one polyclad (von Graff 1903), but they are not detailed enough to make any definite conclusions.

Another interesting observation in the present context was made by von Graff (1882, p. 183), who reported that he often found specimens of Macrostomum hystrix with missing tail-plates. In our view these lesions could be indicative of a thraustochytrid infection (although von Graff attributed them to predating crustaceans). Moreover, we have previously observed the release of thraustochytridlike cells in short-term laboratory cultures of another species of Macrostomum (possibly M. spirale) from a brackish salt marsh in Denmark (L. Schärer, personal observation). Finally, we have observed similar pathologies in a range of Macrostomum species that we have recently collected in the Northern Adriatic, suggesting that our observation is not just a laboratory artifact.

Finally, the fact that we have also observed $T$. caudivorum in our cultures of Isodiametra pulchra, which originate from the coast of Maine (USA), requires some discussion. On one hand it seems possible that this new thraustochytrid species has a wide distribution and that it was collected during the original sampling of this acoel. On the other hand, and we consider this more likely, the cultures of I. pulchra may have been accidentally infested during handling of the laboratory cultures (see also section on control of the thraustochytrids in cultures of M. lignano).

Molecular analysis and phylogenetic placement of $T$. caudivorum

The sequence polymorphisms we observed in the studied fragment of the $18 \mathrm{~S}$ rDNA are intriguing. Given that we used single zoospore cultures for DNA extraction this finding suggests that these polymorphisms do not represent between-strain variation, but that they occur within individual strains. Such polymorphisms are known to occur in individual multinucleate spores of arbuscular mycorrhizal fungi (Glomeromycota). Originally, this inspired a first hypothesis that heterokaryosis occurs throughout the arbuscular mycorrhizal fungal life history (Bever and Morton 1999; Kuhn et al. 2001). However, Pawlowska and Taylor (2004) studied genetic variation in individuals of Glomus etunicatum. They studied of the transmission of polymorphic genetic markers, coupled with direct amplification of rDNA from microdissected nuclei by polymerase chain reaction. Their results support the alternative hypothesis of homokaryosis, in which nuclei populating arbuscular mycorrhizal fungal individuals are genetically uniform. Intrasporal rDNA polymorphism contained in each nucleus would signal a relaxation of concerted evolution, a recombination-driven process that is responsible for homogenizing rDNA repeats. Given that we assume that zoospores are uninucleate the observed polymorphisms would support such a scenario.

Establishment and maintenance of parasite-free cultures

The treatment of eggs with a solution of Triton X-100 proved effective in permanently removing the $T$. caudivorum for the cultures of $M$. lignano. We have in the meantime used this method to establish several different parasite-free cultures of $M$. lignano (some freshly collected from the field) and also a parasite-free culture of M. pusillum (also freshly collected from the field), and all these cultures have to date been maintained for close to a year.

To maintain cultures parasite-free it is essential that working procedures prevent transfer of medium from infested to parasite-free cultures. This is best achieved by using pipettes with disposable plastic tips instead of Pasteur pipettes with pipette bulbs. Medium often enters the pipette bulb and if the medium is contaminated this can lead to the transfer of thraustochytrids between cultures.

\section{Conclusions}

We have identified a new species of thraustochytrid, $T$. caudivorum sp. nov., which appears to be an opportunistic parasite in laboratory cultures of the free-living flatworm $M$. lignano. Affected worms lose the tail-plate and can dissolve completely, while releasing copious amounts of vegetative cells of $T$. caudivorum. We hope that our report will stimulate studies to explore the role of thraustochytrids in the ecology of free-living flatworms and on the influence of free-living flatworms on marine microbial communities. 
Acknowledgments We would like to thank David Porter, Tim James, and Clement Tsui for discussion and two anonymous referees for their valuable comments. Moreover, we would like to acknowledge the tremendous encouragement that we have received in our research from the late Reinhard Rieger. His dear friendship and outstanding scholarship will be greatly missed. During this study L.S. was supported by a Lise-Meitner-fellowship (FWF, Austria), an advanced researcher fellowship (SNF, Switzerland), and a start-up fellowship of the Tyrolean Science Foundation (TWF, Austria). The research was further supported by the FWF grants 15204 and 16618 . Animal experimentation was carried out in accordance with Austrian legal and ethical standards.

\section{References}

Andersen RA, Berges JA, Harrison PJ, Watanabe MM (2005) Recipes for freshwater and seawater media. In: Andersen RA (ed) Algal culturing techniques. Elsevier, Amsterdam, pp 429-538

Bever JD, Morton J (1999) Heritable variation and mechanisms of inheritance of spore shape within a population of Scutellospora pellucida, an arbuscular mycorrhizal fungus. Am J Bot 86:12091216

Bigelow DM, Olsen MW, Gilbertson RL (2005) Labyrinthula terrestris sp nov., a new pathogen of turf grass. Mycologia 97:185-190

Bower SM (1987) Labyrinthuloides haliotidis n.sp. (Protozoa, Labyrinthomorpha), a pathogenic parasite of small juvenile abalone in a British Columbia mariculture facility. Can J Zool 65:1996-2007

Bresslau E (1928-1933) Turbellaria. Walter de Gruyter, Berlin

Craven KD, Peterson PD, Windham DE, Mitchell TK, Martin SB (2005) Molecular identification of the turf grass rapid blight pathogen. Mycologia 97:160-166

Egger B, Ladurner P, Nimeth K, Gschwentner R, Rieger R (2006) The regeneration capacity of the flatworm Macrostomum lignano - on repeated regeneration, rejuvenation, and the minimal size needed for regeneration. Dev Genes Evol 216:565-577

Gardes M, Bruns TD (1993) ITS primers with enhanced specificity for basidiomycetes-application to the identification of mycorrhizae and rusts. Mol Ecol 2:113-118

Hallez P (1879) Contributions à l'histoire naturelle des Turbellariés. Trav Inst Zool Lille Wimereux 2:viii+213, 211 plates

Jensen PR, Jenkins KM, Porter D, Fenical W (1998) Evidence that a new antibiotic flavone glycoside chemically defends the sea grass Thalassia testudinum against zoosporic fungi. Appl Environ Microb 64:1490-1496

Kuhn G, Hijri M, Sanders IR (2001) Evidence for the evolution of multiple genomes in arbuscular mycorrhizal fungi. Nature 414:745-748

Ladurner P, Rieger RM, Baguña J (2000) Spatial distribution and differentiation potential of stem cells in hatchlings and adults in the marine platyhelminth Macrostomum sp.: a bromodeoxyuridine analysis. Dev Biol 226:231-241

Ladurner P, Schärer L, Salvenmoser W, Rieger RM (2005) A new model organism among the lower Bilateria and the use of digital microscopy in taxonomy of meiobenthic Platyhelminthes: Macrostomum lignano, n. sp. (Rhabditophora, Macrostomorpha). J Zool Syst Evol Res 43:114-126
Leander CA, Porter D (2000) Redefining the genus Aplanochytrium (Phylum Labyrinthulomycota). Mycotaxon 76:439-444

Leander CA, Porter D (2001) The Labyrinthulomycota is comprised of three distinct lineages. Mycologia 93:459-464

Leander CA, Porter D, Leander BS (2004) Comparative morphology and molecular phylogeny of aplanochytrids (Labyrinthulomycota). Eur J Protistol 40:317-328

Meixner J (1938) Turbellaria (Strudelwürmer) I. Allgemeiner Teil. In: Grimpe G, Wagler E, Remane A (eds) Die Tierwelt der Nordund Ostsee. Akademischer Verlag, Leipzig, pp 146

Mo CQ, Douek J, Rinkevich B (2002) Development of a PCR strategy for thraustochytrid identification based on $18 \mathrm{~S}$ rDNA sequence. Mar Biol 140:883-889

Pawlowska TE, Taylor JW (2004) Organization of genetic variation in individuals of arbuscular mycorrhizal fungi. Nature 427:733737

Ragan MA, MacCallum GS, Murphy CA, Cannone JJ, Gutell RR, McGladdery SE (2000) Protistan parasite QPX of hard-shell clam Mercenaria mercenaria is a member of Labyrinthulomycota. Dis Aquat Organ 42:185-190

Raghukumar S (2002) Ecology of the marine protists, the Labyrinthulomycetes (Thraustochytrids and Labyrinthulids). Eur J Protistol 38:127-145

Rambaut A (1996) Se-Al: Sequence Alignment Editor

Rieger RM, Gehlen M, Haszprunar G, Holmlund M, Legniti A, Salvenmoser W, Tyler S (1988) Laboratory cultures of marine Macrostomida (Turbellaria). Fortschr Zool 36:523

Rinkevich B (1999) Cell cultures from marine invertebrates: obstacles, new approaches and recent improvements. J Biotechnol 70:133-153

Salamin N, Chase MW, Hodkinson TR, Savolainen V (2003) Assessing internal support with large phylogenetic DNA matrices. Mol Phylogenet Evol 51:112-126

Schärer L, Ladurner P (2003) Phenotypically plastic adjustment of sex allocation in a simultaneous hermaphrodite. Proc R Soc Lond B 270:935-941

Schärer L, Joss G, Sandner P (2004) Mating behaviour of the marine turbellarian Macrostomum sp.: these worms suck. Mar Biol 145:373-380

Spurr AR (1969) A low-viscosity epoxy resin embedding medium for electron microscopy. J Ultrastruct Res 26:31-43

Swofford DL (2003) PAUP* phylogenetic analysis using parsimony (*and other methods). Sinauer Associates, Sunderland

Tyler S (1981) Development of cilia in embryos of the turbellarian Macrostomum. Hydrobiologia 84:231-239

Vilgalys R, Hester M (1990) Rapid genetic identification and mapping of enzymatically amplified ribosomal DNA from several Cryptococcus species. J Bacteriol 172:4238-4246

von Graff L (1882) Monographie der Turbellarien. I. Rhabdocoelida. Willhelm Engelmann, Leipzig

von Graff L (1903) Die Turbellarien als Parasiten und Wirte. Leuschner \& Lubensy's Universitats-Buchhandlung, Graz

White TJ, Bruns TD, Lee S, Taylor J (1990) Amplification and direct sequencing of fungal ribosomal RNA genes for phylogenetics. In: Innis MA, Gelfand DH, Sninsky JJ, White TJ (eds) PCR protocols: a guide to methods and applications. Academic, San Diego, pp 315-322

Zolan ME, Pukkila PJ (1986) Inheritance of DNA methylation in Coprinus cinereus. Mol Cell Biol 6:195-200 